\title{
Examining line as a heuristic device in the design ethos of Alvar Aalto
}

\author{
P. Harwood \\ Department of Architecture, Ball State University, USA
}

\begin{abstract}
The significance of line in Alvar Aalto's design method must be looked at critically as any interpretation of his work lies in the expressionistic, iconological, wavy line sketches so integral to his process. Looking at Aalto's experiments in wood, glass pieces, furniture design, drawings, and built works, I will illustrate that the line is the experimental media that serves as a point of departure for arriving at a symbiosis between nature and culture, defining everything from the topographical character of a roof line to the tectonic form of a door pull. His upbringing, family life, homeland of Finland, and drawing technique all influence his design method and built work. In this paper, the line is explored as a heuristic device provoking questions and providing insight into Alvar Aalto's way of experimenting and intervening in land, in light, and in life. Keywords: regionalism, environmental architecture, Scandinavia, Finland, Alvar Aalto, modernism, architectural design.
\end{abstract}

\section{Experimenting and intervening in land}

The strongest impressions Aalto received were "from his parents, his childhood, and the surroundings he grew up in. These were the sources on which he drew all his life." (Schildt [1]). Born in 1898 in a small village in eastern Finland, Aalto grew up in the town of Jyvaskyla, the unofficial capital of the densely forested Lake District in the heart of Finland. The landscape of this meandering terrain is punctuated by sweeping curves of lakes weaving with forests that lend the region its distinctive character. Goran Schildt has written extensively on the influence of Aalto's contextual and familial background on his tradition of building. Aalto's grandfather was a certified forester and a teacher at Evo Forest 
Institute. Aalto's mother followed in the forestry profession and married the surveyor J.H. Aalto, thus uniting the two disciplines.

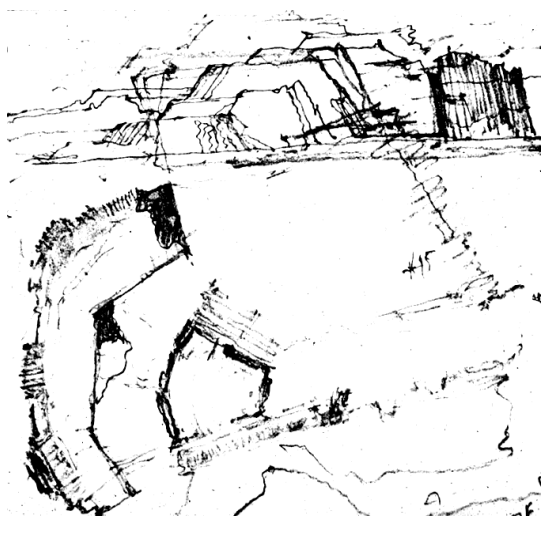

Figure 1: Kiruna Town Hall.

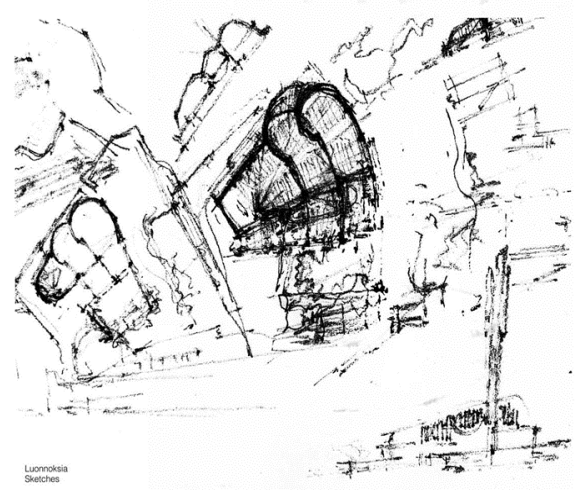

Figure 2: Imatra Church.

\subsection{The contour line}

The effect of his father's surveying practice and mother's forestry background is undoubtedly embodied in Aalto's propensity to use the contour line to delineate both landmass and topographical form. This formative experience provided Aalto with an elementary exposure to native construction materials and techniques, sustainable practices and forestry conservation, as well as acquaintances with drawing and technical factors related to land surveying. In looking at Aalto's concept sketch for the town hall at Kiruna, fig. 1, it is informative to see how strongly the mapmaker's line asserts itself and how he "seems to build up forms as if he were marking the stepping contours of a mountain or hillside," clearly occupying the space of each line as a habitable terrace at vertical intervals as he draws (Hewitt [2], pp.162-176). Suggesting reciprocity between building and landscape, lines of paths, steps, flora and site contours are drawn with equal weight. The sensibility with which Aalto uses this contour line to adapt his buildings to the terrain and the sky and to plan built form and land form as an interwoven fabric is clearly informed by his acquired feeling for the lie of the land and its representation in topographic maps. "There is but one rule holds in architecture, build naturally," writes Aalto. "Our buildings should be placed in the landscape in a natural way, in harmony with its general contours." (Aalto [3], p.21).

Saynatsalo Town Hall illustrates how sensitively the contour line that defines the courtyard promontory rises out of the surrounding forest and acts as the perch upon which the honorific council chamber projects. The fluid contour of the chamber's roofscape greets the sky as a jagged mountain, highlighting the major space within the building from the exterior. Shaping the mass as one would shape the land, the contour line then defines and adjoins entities in a series 
of topographical forms, grouped around the central court. Similarly, the Town Hall at Seinajoki follows the organic pattern established at Saynatsalo, but here a blue-tiled wall is used to order the spaces that surround the inner court. This rustic, grassy, contoured hill steps diagonally up to the ceremonial cliff-like mass of the council chamber and visually connects you to the vertical axis of the bell tower beyond, even as a broad road serves to separate the two. The contour line was a way for Aalto to shape form, unite space and mass, and willingly express how buildings sit in the earth and get rained upon as they silhouette the sky. In material terms, these nitty-gritty issues were abstracted as Aalto took flashings, copings, and base courses and turned them from necessity into poetry.

\subsection{The undulating line}

The irregular coastline, numerous lakes, and seemingly unending wilderness of the Finnish context is of further importance in understanding the alliances Aalto established between the land that he grew up in and the undulating line that characterized his architectural idiom. This context undoubtedly pre-disposed Aalto towards an interest in nature, especially as he sought to create figured interior landscapes in his work. Symbolically, the undulating line between water and land, and forest and clearing became a metaphor for Aalto, translated into the wave-like wall and ceiling of Imatra Church, fig. 2, the sinuous wall of the Worker's Club redbrick façade, and the undulating balcony form of Essen Opera House. More than contriving a stylistic motif, however, this undulating line is intrinsic to Aalto's work as a means to achieve a harmonious accommodation between man and nature (Weston [4], pp.98-122). Aalto writes, "Architecture should always offer a means whereby the organic connection between a building and nature, including man and human life is provided for." (Aalto [5]).

The Finnish Pavilion for the 1937 World Exposition in Paris became Aalto's first unmistakable metaphor of the forest edge. Here, a single, undulating line running diagonally across the rectangular volume becomes the parti for the winning entry entitled Northern Lights. Goran Schildt describes this serpentine space literally as "a forest space, related to the spatial experience of wandering among tree trunks, rocks and bushes in the broken terrain of a Nordic forest." (Schildt [6]). Another metaphor suggested by Richard Weston compares the billowing forest wall and reflective lake floor to a painting of the aurora borealis by Norwegian artist Peder Balke, noting a "striking resemblance to the snaking, closely striated form Aalto adopted." (Weston [7], p.64). Whatever the inspiration, the uniqueness of the Finnish context is illuminated in this inspired installation.

Clearly connected to Aalto's experience of the northern forest, the organic, non-geometrical perception of space acquires particular poignancy in the interior landscape of the Villa Mairea. A common Aalto motif is to cast major internal spaces as 'outdoor rooms' as is seen in the main floor of the villa, where the interior can be read as a metaphoric forest (Weston [7], p.63). Aalto individualized all the columns, singly, in pairs, or in a clump of three, wrapped with rattan, clad with pine slats, or painted black steel, transforming the Cartesian logic of the regular column grid into a series of 'forest fragments.' In 
the undulating screen band that separates the library from the main space, lines of light as rays, streak across the ceiling like sunlight penetrating the forest edge. Commenting on this organic line, Aalto writes, "that curving, living, unpredictable line which runs in dimensions unknown to mathematicians, is for me the incarnation of everything that forms a contrast in the modern world between brutal, mechanicalness and religious beauty in life." (Aalto [3], p.49). When used in conjunction with the familiar contours of the surveyor's line and the gestural sketches of his exploratory design method, the syntax of the undulating line becomes native to his work.

\subsection{The speculative line}

Aalto was compulsively speculative in his design process. His searching, builtup lines were used to contour mass and space in plan and section, often building a figure out of the page as he explored complex formal patterns. The tentative, soft pencil line 'idea sketches' of his projects appear alongside formal presentation drawings, paintings, and photographs of his work in the book Synopsis, that Aalto himself helped lay out (Hoesli [8]). Aalto utilized the 'exquisse' technique, a tiny plan surrounded by projections into section, elevation or perspective, as the starting point for each project (Hewitt [2], p.166). Once he determined his concept through speculative sketching, he would entrust the work to an office assistant who "in close collaboration with Aalto would translate the sketches and pictorial explanations into a presentable conceptual plan." Supervising the intervening stages of design development, Aalto returned to the project at "the phase of cultivating the building with refining details." allowing the distinct Aaltoesque quality of space to become evident. (Fleig [9], p. 9-11).

Aalto favored the soft media of charcoal crayon and the $6 \mathrm{~B}$ pencil for his exploratory line work, suggestive of varying textures of material, flora, and light. Drawing as if by instinct, Aalto's chubby pencil moved fluidly over the paper. His speculative line traversed all corners of the sheet, exploring every aspect of the design, and filling the entire page with multiple representations. "The Creator created paper for drawing architecture on," Aalto exclaims. "Everything else is, for my part at least, to misuse paper." (Aalto [10], p. 7). The childhood experience Aalto recalls most vividly concerns the white table at which his father, mother, and their collaborators worked. "The white table is big, possibly the biggest table in the world. And it stands in the biggest room in my parents' home." As he was to explain later in his career, the white table became a symbol for Aalto, "a neutral plane in combination with man, so neutral a plane that it can receive anything, depending on man's imagination and skill. A white table is as white as white can be, it has no recipe. The white table of my childhood was a big table. It has kept on growing. I have done my life's work on it." (Aalto [3], pp.11-12). Whether drawing a stair rail detail or the building's 'parti', the 'white table of Aalto's childhood' was a way of interrogating the design. Aalto let the speculative, abstract line-work edit his evolving ideas and test the validity of form. (Schildt [11], pp.10-13). In multiple views of the Church of 
Lahti, emerging lines tracing plan shapes, masses, and contours of land and building form are shown with remarkable scalar accuracy. In a rich analysis of Aalto's drawing technique, Mark Hewitt writes, "Although the apparent spontaneity of the line is suggestive of a purely speculative method, most of the published sketches follow a predictable problem solving system" based upon earlier training in surveying and academic architectural design. (Fleig [9]).

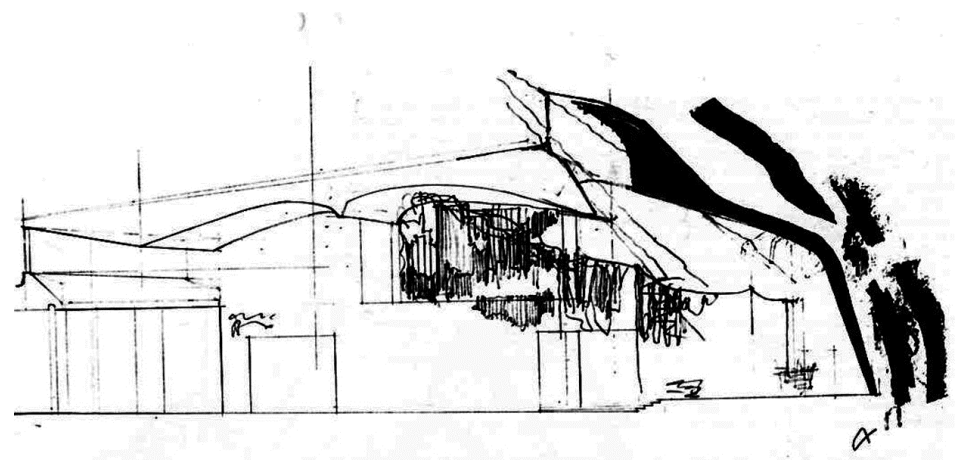

Figure 3: Section of Church of the Three Crosses in Imatra.

\section{Experimenting and intervening in light}

The Nordic experience of light is unique. "The sun does not rise to a zenith but grazes things obliquely and dissolves in an interplay of light and shadow." (Norberg-Schulz [12], p.1). This dispersed light highlights fragmentary and boundless space as places conceal their figural effect, creating spaces of moods and shifting nuances. Aalto's work demonstrates that he had an acute awareness for this quality of light, not only as it occurs in the Finnish landscape and is reflected in his interiors, but also as it relates to humankind spiritually.

\subsection{The double line}

Exploring how we can link the interior and exterior of our homes, Aalto discusses the thick, demarcating line that in Nordic climates "requires a sharp differentiation between the warm interior and the surroundings" and unites the more intimate rooms with the open air (Aalto [3], p.50). Recalling his own childhood home, Aalto believed that when entering a room you should sense the unity of the room, the external wall, and the garden. He understood that the cold climate might do violence to this unity, but that there is nothing wrong with Nordic homes being closed to the outside world. "The Finnish home should have two faces. One is the aesthetically direct contact with the world outside; the other, its winter face, turns inward and is seen in the interior design, which emphasizes the warmth of our inner rooms." (Aalto [3], pp.51-52).

This double-faced line is well illustrated in the Finnish National Pensions Institute in Helsinki. The external façade facing Mannerheimintie reveals an 
austere composition of a ground floor public entrance sheathed in copper and bronze with solid exterior doors, sealed like a vault. Once inside, however, the intermediate space sharply contrasts the somber exterior in material, color, and mood. The main hall beyond is surprisingly arresting, a vast, internal court filled with daylight spilling downward from four large, trough-like, multi-layered skylights. This double line defining two 'shells,' fig. 3, is also used to tremendous success in the Church of Three Crosses at Vuoksenniska where Aalto creates a space of light in the dimension between the interior and exterior walls. Horizontal light, filtered through the birch and pine forest enters high in the double-layered windows of the east elevation, bounces against the shallow white space, and fills the sanctuary with a diffuse 'half-light.' The configuration of the three bulging swells in plan is analogous to the double-line ripples of the sanctuary ceiling. Following this descending, wave-like line in section, the altar roof peaks southward from the crown of the nave like a rock projecting from a shallow river. The formal reference to cascading movement reinforces the meaning of 'vuoksi' as flowing water, the name of the river that runs through Imatra, as well as the Finnish word aalto meaning 'wave' (Nerdinger [13], p.20).

\subsection{The fragmented line}

In Finland, the land of the midnight sun, the diffuse white-light of a summer night is bewitching as the palpable dissolves in an enigmatic shimmer. Something analogous happens in winter when the snow covered earth and large sky vault saturate the night with a peculiar dark light. Indeterminate and fragmentary we inhabit a realm without fixed boundaries or clear geometric form. Things do not appear individually, but are interwoven. Spatially, "we are cleft into fragments of disparate character." (Norberg-Schulz [12], p.6).

This heterotopia of dissimilar entities is a particular curiosity with Aalto's work, as is pointed out by Demetrius Porphyrious. (Porphyrios [14]) In the Cultural Center at Wolfsburg, a number of geometric coherences are brought together as if by chance, be it the radiating fan of lecture rooms or the introverted stepped library and the uneven orthogonal grid of offices. Discontinuities are welcome. There is autonomy within every ordering gesture as fragmentary lines of space and light define an intimately nuanced network of places. The Library at Seinajoki is a similar composition of fragmented lines brought together in light. The spatial organization shows the sunken reading area with its central control desk, a volumetric, figural library hall with a fan-shaped wall admitting dappled sunlight through horizontal louvers, and a low lying block of support spaces. A fragmented, undulating ceiling line distributes reflected light throughout the interior, referencing the typical northern sky of shifting clouds and broken sun (Weston [4], p.184). As these examples illustrate, the building's interior becomes highly differentiated, leaving the monolithic order of Modernism behind. Aalto's use of the fragmentary line lends great variety, spatially, formally, and materially, offering a rich palette to his buildings, capable of adjusting to all sorts of indeterminate circumstances. As Mark Hewitt aptly puts it, "A unity of concept is achieved without sacrificing formal diversity." (Hewitt [2], p.176). 


\subsection{The analytic line}

"I learned - at the age of four, I believe - the philosophy of pencil and paper," Aalto writes (Aalto [3], p.12). Later in life, his acquired sketching penchant was used in conjunction with more formal, analytic design techniques. It is apparent in Aalto's use of simultaneous plan, section, and elevation modes on a single drawing, for instance, that he assimilated well the lessons of the academic classical method from his Beaux-Arts influenced curriculum at the Helsinki Institute of Technology (Schildt [11], pp.68-82). Additionally, Aalto learned the conventions of picturesque composition as we note the perspective views of massing studied within the margins of a page. Aalto's extraordinary synthesis of space/mass composition in his conceptual sketch was the most powerful design tool in his repertoire. Mark Hewitt writes, Aalto's "unique conceptual schema seemed to embrace the poetic qualities of form in drawing while simultaneously adhering to a precise, analytical methodology." (Hewitt [2], p.177). Aalto understood that a loosely drawn sketch might uncover several alternative expressions of formal character and spatial enclosure, while simultaneously helping to refine the space between inner and outer walls and even articulate the acoustic and lighting design. To look at his drawing of space and light in a specific design is therefore informative in understanding this summarizing, analytic line.

"When I designed Viipuri City Library," Aalto writes, "I spent long periods getting my range, as it were, through naïve drawings. I drew all kinds of fantastic mountain landscapes, with slopes lit by many suns in different positions, which gradually gave birth to the main idea of the library building." (Aalto [15], p.97). The spatial order of the library comprises various reading and lending areas, which are stepped at different levels with the administrative and supervisory center at the 'peak.' Layered within this interior landscape, the horizontal ceiling plane is fitted with circular skylights deep enough to prevent direct penetration of sunlight, fig. 5. Aalto's childlike drawings of mountain landscapes were only indirectly linked with the architectural idea of Viipuri, but they led to an interweaving of the section and the plan shape, and to a kind of unity of horizontal and vertical construction (Aalto [15], p. 98). What is most intriguing when tracing the sketches of Viipuri library is the way that Aalto used the line to describe light, sound, and space in at once an analytic and experiential manner. This is seen in Aalto's delineation of the acoustical form for the meeting room as well as the shaping of the conical skylights of Viipuri City Library, fig. 4. Lines of sound, like lines of light are projected and reflected from surrounding surfaces to achieve a unified diffusion in other works as well, most notably the shaping of the curved forms of Vuoksenniska Church and the fan shaped auditoria of Finlandia Hall in Helsinki.

\section{Experimenting and intervening in life}

Believing that "great ideas arise from the small details of life," Aalto always designed with the day-to-day needs of people in mind (Aalto [15], pp. 94-95). 
"My theory are my buildings, I build, that's all," is often quoted to explain Aalto's untheoretical bent and focus on actual construction. Karl Fleig remarked that in the twenty-five years during which he spent countless hours with Aalto, he never talked about architectural theory. "What motivated him were his observations of life. Aalto attempted to invest everything with form." (Fleig [9], pp.9-11) Others have pointed to the emotional qualities of Aalto's expressionistic sketches as crucial to his view of design as an extension of life. "If form somehow fails to be logically connected with everyday life, it will suffer and loose significance," Aalto exclaimed. "There are only two things in art: humanity or not" (Aalto [3], p.183, 202).
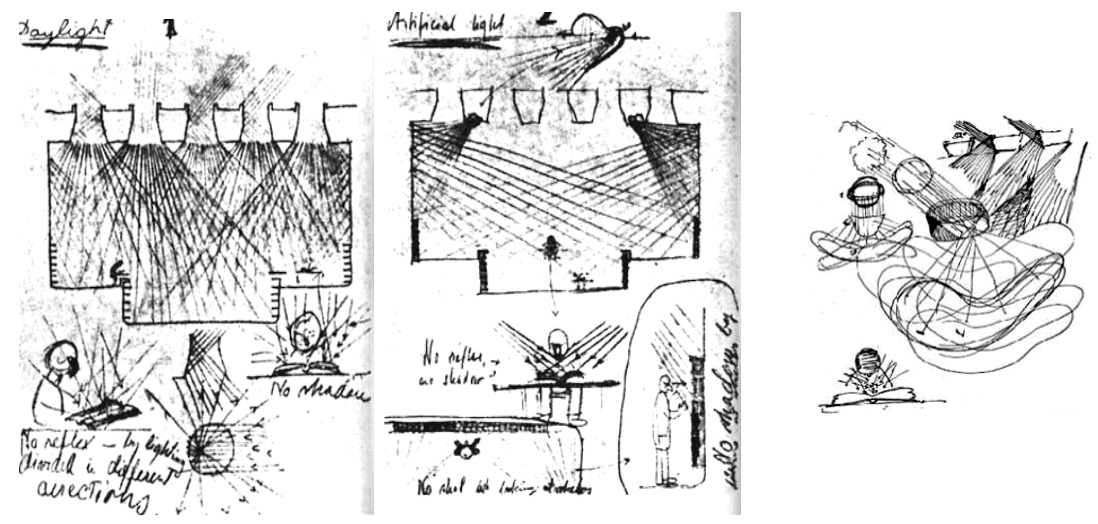

Figure 4: Daylight and artificial light in Viipuri Library.

\subsection{The horizontal line}

At the introduction to a lecture given to his British colleagues in 1950, Leslie Martin, vice president of the Royal Institute of British Architects introduced Aalto by referencing a 'horizontal line.' "Above this horizontal line I would choose to place the creative work of these great designers and below it the rest." (Schildt [11], p.201). Aalto referenced Martin's horizontal line in the same lecture saying, "The real line is to plan and to build for the little man, for his benefit." (Aalto [3], p.204). Thinking about what people need, fresh air, daylight, gardens and forests, Aalto writes, "it is from these little things that we should build up a harmonious world for the people. This would be possible if everybody tried to get the people who are in the administration to just follow our line." (Schildt [11], p.205). In the attention that Aalto played to the little things, from the tactile quality of a double door handle at a library to the dampened sound of splashing water in a washbasin at a hospital, it is apparent that he never forgot that he was designing for human beings. Here we are again reminded of Fleig's comment that Aalto had "little time for formal architectural theories; only life that is lived and observed can furnish guidelines." (Fleig [9], p.9).

Life did offer guidelines for Aalto in the design of Paimio Sanitarium for he was ill at the time of its design. "It irritated me to lie horizontal all the time and 
the first thing I noticed was that the rooms were designed for people who spend their days in a vertical position, not for those who have to spend days on end in bed." (Aalto [3], p.178). As a foundation for the humanizing of architecture, Aalto based his design on this horizontal line of reclining patients. He designed the lighting to be outside patients' field of view, ceiling heating to be directed toward patients' feet, the ventilation of special opening casement windows to avoid drafts, the ceilings to be painted in dark, restful colors, the communal floor surfaces to be bright yellow linoleum to promote a sunny and upright disposition, sun loungers to be wheeled out to the open air terraces at the east end of each floor, and a wave-like chair with molded arm rests and a laminated wood supporting system to resiliently receive the occupant (Aalto [15], pp.76-79).

\subsection{The meandering line}

The naturally flowing, seemingly self-evident, meandering line of movement is an important design element with which Aalto relates buildings to human beings. Aalto understood the way we orient in the density of the Finnish forest and in the uninhibited thickness of human life. We wander, because things are not precise. In this meandering line of movement, we come to find our way. As an expression of life and motion, Aalto's 'forest spaces' allow us to find a tentative, wandering way. One never moves along an axial line, following an orthogonal route system from one point to another. Instead, the line of movement constantly turns off in a different direction, with the vitality and variety of nature expressed in the freedom of modulated and attenuated space (Nerdinger [13], pp.20-24). Like the asymmetrical fan-like form akin to many of his works, the flow of movement is like a subsiding wave, pulsating in and out, up and down, forward and backward.

Aalto translates the everyday movements of people into architecture, applying this principle particularly well to the design of interior landscapes. In the figured space of Finlandia Hall, we see how the rectilinear concert hall forms are thrust into the public space creating wave-like, billowy lines of access, lending the interior a feeling of natural form and movement. This meandering line can also be seen in the form and experience of the Baker House Dormitories at Massachusetts Institute of Technology where every step and view is carefully choreographed. "The starting point of Aalto's design was to place the living accommodation as well as possible in relation to the river," Elina Standertskjold noted. "He made dozens of sketches and finally adopted an unusual plan in which the narrow spine of the building twists in parallel with the river road." (Standertskjold [10], pp.56-63). This serpentine form resulted in an individual view of the Charles River from every room, wandering passages between public and private spaces, and an organic contrast to the rectilinear design of the MIT campus.

\subsection{The indivisible line}

Aalto regarded everything that touches human life as a task for the architect and he referred to this process as the total synthesis (Fleig [16]). Seeing architecture as a single indivisible line, from painting to urban planning to experiments in 
wood to the design of a staircase balustrade, is a special quality of Aalto's work. Aalto understood every construction as an integrated whole, designing everything down to the smallest detail himself. Commenting on the inseparability of art forms, Aalto writes, "Paintings and sculptures are all part of my working method. So I wouldn't like to see them separated from my architecture. To me these works are all branches of the same tree, the trunk of which is architecture." (Aalto [3], p.40). In much the same way as Aalto's paintings experiment with the natural metaphors of form and movement, Aalto's bent wood studies and furniture design subtly but effectively transform industrialism into a harmonious quality of civilization. The fusion of sketching, painting, sculpture and architecture yields a dense web and complex mode of conception where the line is a unique heuristic device allowing Aalto out of the 'maze' when he gets that kind of "three in the morning feeling." Aalto writes, "I forget the whole maze of problems for a while. I then move into a method of working that is very muck like abstract art. I simply draw by instinct, and in this way, on an abstract basis the main idea gradually takes shape." (Aalto [3], p.108). Then "one tackles the material. Through application the ideas will become more concrete and realistic. The three art forms, architecture, painting, sculpture, are connected because they are an expression of human intellectuality based on 'materia."' (Aalto [3], p.267) Idea becomes reality as the indivisible line takes material form.

\section{Conclusion: "Following the Line"}

Aalto was fascinated by lines; as the strata and contours of the earth, as manifestations of natural forces, as expressions of meandering movement, as undulating wave-like spaces, even as striations of an uneven brick façade. In all his works, Aalto writes, he sought to "accentuate the lines of square and street perspectives. In the country, their function is to accentuate the landscape." (Aalto [3], p.22) Uniting building and landscaping with a cartographers eye, combining speculation with rationality in an imaginative way, harmonizing space and mass with environmental sensitivity, and fusing form and function with remarkable human compassion, Aalto used the line in a heuristic way. What makes the line magical, Marja-Riitta Norri, director of the Museum of Finnish Architecture ponders? "The line contains human thought, it carries the mark of the hand that drew it; they combine into a single living material that goes to build the real world." (Norri [3], p.9) Aalto's theory is his process, he builds when he draws!

\section{References}

[1] Schildt, G., "Alvar Aalto's teachers - three leaves from the book of his life," Alvar Aalto 1898-1976, ed. Aarno Ruusuvuori, The Museum of Finnish Architecture: Helsinki, pp. 13-21, 1978.

[2] Hewitt, Mark A., "The Imaginary Mountain The Significance of Contour in Alvar Aalto's Sketches," Perspecta 23 The Yale Architectural Journal, 
eds. M. Chapman, B. Rubenstein and S. Wright, Rizzoli International Publications: New York, 1989.

[3] Aalto, A., Alvar Aalto In His Own Words, ed. Goran Schildt, trans. Timothy Binham, Rizzoli International Publications: New York, 1997.

[4] Weston, R., Alvar Aalto, Phaidon Press Limited: London, 1995.

[5] Aalto, A., "Nature and Architecture," Alvar Aalto 1898-1976, ed. Aarno Ruusuvuori, The Museum of Finnish Architecture: Helsinki, p. 34, 1978.

[6] Schildt, G., Alvar Aalto: The Decisive Years, trans. Timothy Binham, Rizzoli International Publications: New York, pp. 131-132, 1986.

[7] Weston, R., "Between Nature and Culture: Reflections on the Villa Mairea," Alvar Aalto: Toward a Human Modernism, ed. Winfried Nerdinger, Prestel Verlag: Munich, London, New York, 1999.

[8] Hoesli, B. Alvar Aalto: Synopsis, Birkhauser Verlag: Basel, Boston, Stuttgart, p. 5, 1980.

[9] Fleig, K., Alvar Aalto: Volume II, 1963-70, Artemis: Zurich, 1971.

[10] Aalto, A., The Line: Original Drawings from the Alvar Aalto Archive, ed. K. Paatero, trans. H. Hawkins, Helsinki, 1993.

[11] Schildt, G., Alvar Aalto: The Early Years, trans. Timothy Binham, Rizzoli International Publications: New York, 1984.

[12] Norberg-Schulz, C., Nightlands: Nordic Building, trans. Thomas McQuillan, MIT Press: Cambridge, London, 1996.

[13] Nerdinger, W., “Alvar Aalto's Human Modernism," Alvar Aalto: Toward a Human Modernism, ed. Winfried Nerdinger, Prestel Verlag: Munich, London, New York, 1999.

[14] Porphyrios, D., "The Ordering Sensibility of Heterotopia," Sources of Modern Eclecticism, St. Martin's Press: London, pp. 1-8, 1982.

[15] Aalto, A., "The Trout and the Mountain Stream," Sketches: Alvar Aalto, ed. Goran Schildt, trans. Stuart Wrede, MIT Press: Cambridge, London, 1978.

[16] Fleig, K., Alvar Aalto: Volume I 1943-63, p. 6, 1995. 